\title{
A IMPORTÂNCIA DO PLANEJAMENTO TRIBUTÁRIO DAS MICRO E PEQUENAS EMPRESAS PARA O CRESCIMENTO E DESENVOLVIMENTO DAS CIDADES MÉDIAS
}

\author{
The Importance of Tax Planning for Micro and Small Enterprises for the Growth and \\ Development of Medium-sized Cities
}

\section{La Importancia de la Planificación Tributaria de las Micro y Pequeñas Empresas para el crecimiento y el desarrollo de las ciudades medianas}

Rodrigo de Souza Costa ${ }^{1}$

Josenaldo de Souza Alves ${ }^{2}$

\footnotetext{
${ }^{1}$ Graduando em Ciências Contábeis pela Faculdade Independente do Nordeste - FAINOR, josenaldo1@yahoo.com.br

${ }^{2}$ Professor Mestre do Curso de Ciências Contábeis da Faculdade Independente do Nordeste - FAINOR, e-mail josenaldo@fainor.com.br
}

\section{Resumo}

O presente artigo demonstra a importância do planejamento tributário para as micro e pequenas empresas, enquanto estratégia de desenvolvimento das cidades médias. Como metodologia, utilizou-se o método qualitativo, para em seguida, realizar as análises pertinentes e as discussões necessárias para a apresentação dos resultados. Os resultados apontam que há, portanto, uma necessidade de um bom planejamento tributário para as micro e pequenas empresas, de forma a gerar reais chances de se manterem no mercado com sucesso e dentro das bases legais, sem a excessiva oneração dos seus custos, o que permitiria melhores resultados para a empresa e uma maior arrecadação tributária pelo ente público, os quais seriam investidos em serviços nos centros urbanos.

Palavras-chave: Cidades Médias; Microempresas; Planejamento Tributário.

\begin{abstract}
The present article demonstrates an important of tax planning for how micro and small enterprises, while the strategy of development of medium cities. As methodology, the qualitative method was used, instead, to perform as relevant analyzes as discussions for a presentation of the results. The results are as high as more, therefore, the need for a good tax planning for micro and small companies, in order to generate real chances of remaining in the market successfully and within the legal bases, without an excessive burden of their costs, which would allow better results for a company and a greater tax collection by the public entity, which would be invested in our urban centers services.
\end{abstract}

Keywords: Medium Cities; Microenterprises; Tax Planning

\section{Resumen}

El presente artículo demuestra un importante de la planificación tributaria para las micro y pequeñas empresas, mientras que la estrategia de desarrollo de las ciudades medias. Como metodología, se utilizó el 
método cualitativo, para en lugar, realizar como análisis relevantes como discusiones para una presentación de los resultados. Los resultados son tan elevados cuanto más, por lo tanto, la necesidad de una buena planificación tributaria para las micro y pequeñas empresas, para generar reales posibilidades de mantenerse en el mercado con éxito y dentro de las bases legales, sin una excesiva carga de sus costos, lo que permitiría mejores resultados para una empresa y una mayor recaudación tributaria por el ente público, los cuales ser invertidos en servicios a nuestros centros urbanos.

Palabras clave: Ciudades medias; Microempresas; Planificación Tributaria.

\section{Introdução}

A carga tributária do país tem sido alvo de constantes questionamentos por parte da sociedade, sobretudo porque impede o crescimento das micro e pequenas empresas. São tantas as limitações e restrições para que tais empresas optem por determinado regime de tributação, que os impostos e contribuições unificados apenas facilitam a apuração, mas não reduzem, de forma significativa, os tributos que as oneram. Há, portanto, a necessidade de um bom planejamento tributário para as micro e pequenas empresas, o qual promoverá grandes chances de se manterem no mercado com sucesso, dentro das bases legais e contribuindo para o crescimento e desenvolvimento das cidades em que atuam, uma vez que os índices de inadimplência tendem a reduzir.

No contexto em que as micro e pequenas empresas atuam as cidades médias possuem fundamental papel no desenvolvimento das regiões e do país e, para o desenvolvimento dessas cidades, necessita-se de organizações fortes, estruturadas e geridas de forma a manter-se competitivas no mercado. A carga tributária do Brasil, no entanto, sobrecarrega as organizações, principalmente, as micro e pequenas empresas, causando, dessa forma, um alto percentual de inadimplência e a falência de muitas delas. Os dados ratificam o exposto na medida em que o número de empresas inadimplentes bateu recorde nos últimos anos. De acordo com estudos do Serasa, em abril de 2016, apontou que 4,4 milhões de empresas estão negativadas, das cerca de 8 milhões em operação no cenário nacional (SERASAEXPERIAN,2016). Ou seja, mais de $50 \%$ das empresas em atividade, encontram-se inadimplentes, o que implica em prejuízos às empresas e aos investimentos em infraestrutura urbana, sobretudo das cidades médias, que têm como missão de fomentar a qualidade de vida de diversas cidades e da sua rede de empresas uma vez que, recolhidos menor valor em tributos, menores os investimentos coletivos serão realizados.

O planejamento tributário está diretamente relacionado à possível margem de lucro, já que possibilita a redução de impostos por meio de suas ações. Segundo Martins 
(2009) as ações do planejamento são de três ordens: anulatória (impede a incidência do tributo), edutiva (emprega formas jurídicas que diminuem o valor de um tributo) e postergativa (retarda o pagamento do tributo), que podem ser feitas separada ou conjuntamente. Leve-se em conta que em algumas situações o ônus não está diretamente ligado ao tributo, mas a deveres fiscais secundários como, por exemplo, a apresentação de documentos e as despesas contábeis (MARTINS, 2009). O planejamento tributário é, portanto, uma ferramenta valiosa para as empresas, que, através de seu minucioso estudo possibilita escolher o sistema de tributação que mais se adequa a sua realidade (FABRETTI, 2006).

Caso a escolha do planejamento tributário seja equivocada, a empresa sofrerá as penas durante todo o exercício, uma vez que a legislação só permite a mudança de regime a cada novo exercício. Sobre as micro e pequenas empresas, visando diminuir o peso dos seus tributos, foi criado o Simples Nacional ou Super Simples. Trata-se de um sistema de tributação que beneficia tais empresas de diversas formas, com alíquotas diferenciadas e com vantagens no recolhimento de todos os tributos federais, estaduais e municipais em uma única guia.

O planejamento tributário, quando bem elaborado e administrado, contribui para modificar a gestão dos tributos, orientando a empresa e reduzir os impactos causados pelos tributos, de forma legal. Trata-se, portanto, de uma atividade preventiva, que funciona como suporte à tomada de decisão, evitando que o empresário possa praticar atos que não estejam amparados legalmente, poupando-o ainda, de cobrança excessiva por parte dos órgãos fiscalizadores.

Atualmente, vários estudos comprovam que um grande número de empresas falha no momento da escolha sobre qual regime de tributação irá optar quando do enquadramento fiscal, gerando sofrimento às empresas devido à cobrança excessiva dos tributos. Em consequência, muitas dessas empresas e profissionais contábeis, em função da falta de planejamento, recorrem a atos ilícitos e sofrem dificuldades para honrar os seus compromissos, resultando no encerramento das suas atividades prematuramente.

Desta forma, ante o exposto, este artigo evidencia o tema em questão, por meio do seguinte questionamento: Qual a importância do planejamento tributário das micro e pequenas empresas em cidades médias? Para responder as esta questão, estabeleceu-se como objetivo geral demonstrar a importância do planejamento tributário para as microempresas como forma de colaborar para a melhoria de infraestrutura das cidades médias. Como objetivo específico propõe-se apresentar conceitualmente as 
microempresas e pequenas, correlacionando suas contribuições com o crescimento e desenvolvimento das cidades médias; caracterizar o planejamento tributário quanto aos aspectos conceituais; identificar e analisar os regimes tributários em vigor no país e identificar a tributação mais adequada para as microempresas, visando a redução de custos com os tributos.

Para desenvolvimento da pesquisa, enquanto procedimento metodológico, o estudo se desenvolveu a partir de análise bibliográfica, onde utilizou-se o método qualitativo, analisando estudos sobre a temática apresentada, o que permitiu o estabelecimento de algumas considerações. Também, utilizou-se como levantamento de instrumentos de informações, portanto, a pesquisa bibliográfica, tendo como base de informações livros, artigos, revistas especializadas, o Código Tributário Nacional e a Constituição Federal. Esse tipo de pesquisa procura elucidar um problema a partir de referências teóricas publicadas em outros documentos.

\section{Cidades Médias}

Os conceitos sobre cidade média, segundo estudos apresentados pela literatura, modificaram-se no contexto histórico. Tal situação tem provocado diferentes e evolutivos posicionamentos. Embora se verifique o aumento da quantidade de pesquisas, as concepções sobre cidades médias continuam gerando opiniões diversas. Santos (2012) afirma que:

As cidades médias são aquelas que exercem a função de um centro regional numa determinada dinâmica da rede urbana, de acordo com o potencial demográfico, a situação, o raio de ação e o nível de especialização dos serviços e das atividades produtivas. Além disso, têm a capacidade de articular-se aos centros de decisões sem, necessariamente, depender das cidades dentro da sua unidade político administrativa, cuja ordem hierárquica seja superior, como as grandes e as metrópoles. (SANTOS, 2012, p. 134)

Para Alves (2014), a justificativa pela busca da compreensão de uma concepção sobre cidades médias, pode estar na potencial descoberta de uma maior interação que envolve a questão social, econômica e ambiental entre seus habitantes e os habitantes da sua região de influência. Esta concepção conduziria a distinção "cidade média" das pequenas e grandes cidades, em função da sua capacidade de disponibilizar algumas infraestruturas e equipamentos necessários ao desenvolvimento humano e qualidade de 
vida, além da intermediação das hierarquias urbanas. É neste cenário que se desenvolvem as transformações nas cidades médias, marcadas mais recentemente pelo processo de globalização pelo qual o mundo vivencia. Transformações essas que aprofundam a integração econômica, social, cultural e política da sua população.

Destaque-se, ainda, que o acelerado processo de urbanização pelo qual o mundo tem passado, vem despertando o interesse de muitos pesquisadores pelo tema cidades médias. Um das hipóteses mais prováveis para tal motivação, é que a discussão sobre as características deste perfil de cidades tem fomentado o debate acerca das possibilidades de busca por uma melhor qualidade de vida da sua população e daqueles que vivem na sua hinterlândia. Tal condição impele a população a um processo de migração, o qual exige que tais cidades disponham de investimentos capazes de proporcionar maior qualidade de vida aos mesmos. Aspectos, portanto, relacionados à qualidade de vida das cidades, às formas de organização do seu espaço demográfico e os aspectos econômicos, de caráter intra e interurbano, integram desafios desta categoria de cidades na rede de localidades centrais no mundo, sendo imperativos na necessidade de previsão de investimentos públicos em infraestrutura e equipamentos urbanos, os quais dependem, sobremaneira, dos recursos tributários gerados pelas empresas.

A busca, portanto, pela compreensão do que pode significar cidades médias, possibilita estabelecer uma maior conexão social, econômica e ambiental entre seus habitantes e os habitantes da sua região de influência. Esta concepção conduziria a certo arquétipo de funcionalidade que as distinguiriam das pequenas e grandes cidades, em função da disponibilidade de determinadas infraestruturas e equipamentos, além da capacidade de intermediar as hierarquias urbanas. Tal condição agregaria fatores qualitativos à qualidade de vida da população, extensivos, inclusive, nos níveis regional, nacional e internacional.

Estabelecer uma conexão entre a temática "Cidade Médias" e "Planejamento Tributário" constitui-se em um desafio singular de importância impar à compreensão de como tal ferramenta pode funcionar como uma grande aliada no fomento à melhoria da qualidade de vida de uma cidade. Desafio posto, segue-se adiante.

\section{Planejamento tributário}

O planejamento tributário nas microempresas assegura o correto cumprimento das obrigações fiscais, destacando a importância da redução da carga tributária no país e 
prevendo alternativas de escolhas lícitas que conduzem ao resultado fiscal das microempresas aos resultados desejados (FABRETTI, 2006). Neste contexto, pode-se definir planejamento tributário como um processo de escolha e uma ferramenta de gestão, a qual objetiva viabilizar a redução de custos geradores pelos tributos. Para Borges (2002, p. 56) planejamento tributário conceitua-se:

Uma técnica gerencial que visa proteger as operações industriais, os negócios mercantis e as prestações de serviços, visando conhecer as obrigações e os encargos tributários inseridos em cada uma das respectivas alternativas legais pertinentes para, mediante meios e instrumentos legítimos, adotar aquela que possibilita a anulação, redução ou adiamento do ônus fiscal.

Planejar é, portanto, escolher entre opções lícitas aquela que possa oferecer melhores resultados a entidade. Ou seja, é uma importante ferramenta para redução de custos. Nesta direção, Nogueira (2010, p. 202) declara que:

\begin{abstract}
Ninguém é obrigado a escolher, entre várias formas possíveis, aquela que seja sujeita a impostos mais altos [....], pois a possibilidade de uma estruturação, que em face da legislação tributária seja mais favorável, corresponde ao interesse justo do contribuinte, reconhecido pela ordem jurídica.
\end{abstract}

Nas micro e pequenas empresas, a ausência de planejamento tributário colabora para que as mesmas fiquem em desvantagens quanto à competitividade de mercado. Todavia, tais empresas, ao fazer uso do planejamento tributário, possui uma enorme perspectiva de lucros em relação a seus concorrentes (BORGES, 2002). Em suma, planejamento tributário é planejar como pagar, legalmente, menos impostos, ou seja, é utilizar-se de meios legais que permitam a redução do valor a ser pago dos tributos.

Para a realização de um sistema de planejamento tributário eficaz, é imprescindível que sejam considerados todos os tributos incidentes na operação empresarial. Assim, após a análise individual do tributo, é possível confrontar a redução do ônus fiscal individual com os reflexos nos outros tributos. O planejamento é, assim, usado pela empresa para a redução de seus próprios custos tributários, por meio da fórmula: redução do custo, ganho de escala, diminuição do preço de venda, ganho de mercado (NOGUEIRA, 2010).

Já Oliveira (2009, p. 205) assevera que,

Para obtenção de uma eficácia da economia legal de impostos e contribuições, também a integração de todos os departamentos da empresa é necessária. Não adianta ter um comitê interno de 
planejamento, se as decisões forem tomadas sem o conhecimento de pessoas importantes para o sucesso.

Oliveira (2009) ainda afirma que "o planejador ou gestor tributário deve ter em mente que o elemento diferenciador não é a informação, mas sim a capacidade de transformá-lo em conhecimento". Dessa forma, não basta o contato apenas com ideias criativas. Necessita-se, ainda, observar algumas regras básicas já aplicadas pelas organizações empresariais à frente do processo de elaboração de planos voltados à legítima economia de tributos. Assim, o planejamento tributário exige uma soma de conhecimentos, tais como o contábil e o jurídico. Contábil porque, além da intimidade com a legislação fiscal, o profissional identifica, com mais facilidade, o processo operacional da empresa, os fatos geradores de tributos e jurídico, porque o advogado tem o conhecimento jurídico, consegue identificar na legislação tributária as oportunidades de redução da carga tributária (CHAVES, 2008).

\section{Vantagens de um planejamento tributário eficaz}

Em um país competitivo, mas detentor de altas mortalidades das micro e pequenas empresas é preciso que se compreenda, de modo eficaz, o planejamento tributário, de maneira que não cometa atos ilícitos, causando assim uma evasão fiscal e, em consequência, ocasionando uma fiscalização direta ou indireta do Estado, União e Municipal (AMARAL, 2011).

Desta forma, torna imprescindível adotar um sistema de economia legal, visando encontrar mecanismos que permitam um menor desembolso financeiro com pagamento de tributos. Se a empresa pretende economizar seus encargos tributários, poderá fazê-lo de forma eficaz e legal. A maneira legal chama-se economia legal (planejamento tributário) a eficaz minimização dos custos (lucro). Cabe destacar que se a forma celebrada é jurídica e lícita, a fazenda deve respeitá-la (GRECO, 2009).

Acrescenta-se, de acordo com a assertiva de Oliveira (2005), que a eficácia de um gestor tributário não está na tomada de decisão visando à economia de determinado tributo, se ele desconhece os aspectos do seu cliente como seu porte, regime tributário, localização geográfica.

Portanto, se a empresa conseguir realizar um planejamento tributário eficaz poderá usufruir de inúmeros benefícios, tais como: O estabelecimento de uma vantagem competitiva da empresa frente aos concorrentes. - o fortalecimento da empresa para 
suportar as ameaças do mercado; - evitar os atos ilícitos, que prejudicam terceiros e enganam o fisco, evitando assim infrações fiscais ou penais; - minimizar os erros presentes que refletem no futuro, ocasionado as mortalidades. - diminuição dos ônus tributário, aumentando a lucratividade; $\mathrm{O}$ bom condicionamento da empresa para que ela possa estar sempre bem preparada para as mudanças tributárias; - a condição de que os administradores tenham uma visão clara do regime de tributação do qual a empresa está ingerida e seus tributos; O auxílio da melhor compreensão e interpretação da lei (GRECO, 2009).

Ainda na afirmação de Oliveira (2009) as normas que compõe o sistema tributário Nacional, são instáveis dificultados o acompanhamento e o ritmo de suas alterações, o que evidencia a necessidade de adoção de um planejamento tributário eficaz, capaz de superar todas as dificuldades para conhecer as normas tributárias e mostrar outros caminhos econômicos. Ao tornar-se cada vez mais minucioso e profundo esse procedimento, é possível detectar os efeitos tributários em qualquer operação que empresa venha a praticar e apontar a alternativa mais viável que possa ser adotada.

A importância do planejamento tributário, portanto, está em seu caráter preventivo, decorrendo do fato de não se poder escolher alternativas, senão antes de se concretizar a situação. Com a consolidação dos fatos, normalmente, somente há duas alternativas: pagar ou não pagar o tributo decorrente da previsão legal descrita como fato gerador. Mas, a opção de não pagar se caracterizará como prática ilícita, sujeitandose a organização à ação punitiva do Estado, caso este venha a tomar conhecimento de tal prática.

\section{Microempresas no contexto do planejamento tributário}

De acordo com Instituto Brasileiro de Geografia e Estatística (IBGE), o capitalismo moderno é caracterizado pela concentração de grandes empresas que têm como fundamento a economia de escala, na qual a rentabilidade aumenta de acordo com a redução do custo do processo produtivo. Contudo, as Pequenas e Medias Empresas conseguiram alcançar um lugar de destaque no mercado, principalmente no segmento de serviços e comércio (IBGE, 2014). Neste contexto, O número de empregados e o faturamento bruto anual são os critérios mais utilizados para definir o porte das empresas, conforme pode ser demonstrado nos quadros abaixo. 
Quadro I- Classificação das ME segundo o número de empregados

\begin{tabular}{|c|c|}
\hline Porte & Empregados \\
\hline Microempresa & $\begin{array}{l}\text { No comércio e serviço até } 09 \text { empregados. } \\
\text { Na indústria até } 19 \text { empregados. }\end{array}$ \\
\hline Empresa de pequeno porte & 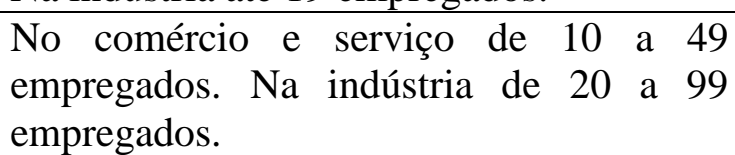 \\
\hline Empresa de médio porte & $\begin{array}{l}\text { No comércio e serviço de } 50 \text { a } 99 \\
\text { empregados. Na indústria de } 100 \text { a } 499 \\
\text { empregados. }\end{array}$ \\
\hline Empresa de grande porte & $\begin{array}{l}\text { No comércio e serviço mais de } 99 \\
\text { empregados. Na indústria mais de } 499 \\
\text { empregados. }\end{array}$ \\
\hline
\end{tabular}

Fonte: Lei Federal no. 9.841, de 05/10/99 (Estatuto da Micro e Pequena Empresa).

Quadro II - Classificação das ME segundo o faturamento bruto anual:

\begin{tabular}{|l|l|}
\hline \multicolumn{1}{|c|}{ Porte } & Faturamento Bruto Anual \\
\hline Microempresa & Até $\mathrm{R} \$ 360.000,00$ \\
\hline
\end{tabular}

Fonte: Lei Federal no. 9.841, de 05/10/99 (Estatuto da Micro e Pequena Empresa).

A microempresa vem sendo extremamente importante para a economia brasileira ao longo dos anos. Segundo dados do IBGE, $21 \%$ do Produto Interno Bruto (PIB) era oriundo destes negócios, em 1985. Já em 2001, essa participação cresceu para 23,2\%, enquanto em 2011 foi para 27\% - dados que evidenciam sua importância para a economia brasileira (IBGE, 2014). Dessa forma, cada vez mais as micro e pequenas empresas ganham mais relevância, devido a sua colaboração para diversos setores de base do país. Segundo o último levantamento publicado pelo Serviço Brasileiro de Apoio as Microempresas (SEBRAE), em julho de 2014, o Brasil abriga cerca de 8 milhões de micro e pequeno negócios - que empregam $52 \%$ dos trabalhadores com carteira assinada (SEBRAE, 2016).

Apesar de toda a importância evidenciada acima, o Brasil não tem uma estrutura que facilita a vida do microempresário. A soma dos procedimentos para a abertura de empresas no Brasil demanda muito tempo, esforço, não só financeiro, como intelectual - recursos que são extremamente importantes para as novas empresas, que poderiam ser utilizados para expandir e melhor o próprio negócio.

A burocracia brasileira, muitas vezes, é um fator tão desestimulante que, para muitos empreendedores, ao ver tanta dificuldade apenas para começar a empreender, desistem de enfrentar o processo de abertura de suas empresas, operando na informalidade, correndo riscos de sobrevivência e, principalmente, limitando o crescimento do negócio. Adicione-se que, em 2016, constatou-se que o Brasil encontrase em um momento de crise econômica. Inflação prevista aproximando-se dos dois 
dígitos, juros mais altos, dificuldade de acesso ao crédito, diminuição do poder de compra dos consumidores, aumento e criação de novos impostos são consequências que afetam diretamente o microempresário (IMPE/SEBRAE, 2016).

Ante tais fatos, as microempresas têm um papel fundamental para alavancar o crescimento do País, por meio dos ambientes em que atual. Ou seja, em sua maioria, nos centros urbanos. Os pequenos negócios são de grande importância para fomentar o desenvolvimento e contribuir com o avanço do nosso país, criando novos empregos e aumentado a renda do povo e melhorando as condições de vida da população, por meio de implantação e melhoria da infraestrutura e dos equipamentos urbanos. A contribuição das microempresas na economia são, portanto, reconhecidas na absorção de mão de obra, inclusive aquela com maior dificuldade de inserção no mercado, como jovens em busca pelo primeiro emprego e as pessoas com mais de 40 anos. As pequenas empresas também são capazes de dinamizar a economia dos municípios e bairros das cidades médias e grandes.

\section{Planejamento Tributário no contexto das micro e pequenas empresas}

Em um país, como o Brasil, onde a carga tributária é elevada e as mudanças na legislação são constantes, é um grande desafio as Microempresas se manterem no mercado; embasados em atos lícitos, por meio do o planejamento tributário (YOUNK, 2009). Concordando com Teixeira (2009, p. 205):

\footnotetext{
A realidade é que todas as empresas, tanto as micro e pequenas quanto as grandes, atordoadas com a carga tributária existente, comprovam a necessidade urgente de adoção de procedimentos legais que obtenham resultados concretos de redução do custo tributário. O planejamento tributário não é ficção ou mero modismo, muito menos a carga tributária brasileira, que a cada dia vem cerrar as portas de inúmeras empresas, desempregando milhares de pessoas e travando o desenvolvimento econômico do país. É sim, realidade, e mais que isso, necessidade e questão de sobrevivência.
}

O constante crescimento da participação dos tributos brasileiros na formação de preços dos produtos e serviços oferecidos está aliado ao fato de que a competitividade no mercado requer cada vez mais esforços criativos, inovadores e dinâmicos de estratégia das empresas (ZAPATEIRO, 2007). Assim o planejamento tributário, ferramenta imprescindível ás entidades, consiste no fato de que, todos os contribuintes, tem o direito de realizar negócios, sem se onerar demasiadamente com tributos, de 
forma que paguem o mínimo exigível em face de uma determinada legislação (OLIVEIRA, 2009).

Diante dos fatos abordados é relevante que os gestores das ME busquem realizar um planejamento tributário eficaz, visando o informações adequadas que irão auxiliar nas tomadas de decisões, a fim de minimizar os tributos, trazendo assim, vantagem competitiva no mercado (MARTINS, 2009).Existe a necessidade, ainda, de cada vez mais desburocratizar o Sistema Tributário e da realização da Reforma Tributária, a fim de racionalizar a incidência da carga tributária sobre as empresas e ampliar o potencial de crescimento do país, pautado nos limites de tributação pelos entes federados com apoio nos princípios da capacidade contributiva, do mínimo existencial, da igualdade, razoabilidade, proporcionalidade, dentre outros, para se evitar a arbitrariedade por parte do Estado (OLIVEIRA, 2009).

Há, contudo, uma grande dificuldade para interpretação da legislação tributária e, não bastasse isso, ainda são constantes as alterações na legislação pertinente. Tal fato exige que o profissional da área esteja em constante processo de atualização de seus conhecimentos. (SIQUEIRA, 2011). Na legislação tributária, interpretar é descobrir o sentido e alcance da norma jurídica. Qualquer objeto cultural está impregnado de significados que requerem interpretação, tornando claro e límpido, ou não, o que, de início, parecia confuso. O Direito não foge à regra. Para se aplicar a norma, é preciso fixar o seu sentido, descobrindo sua finalidade e apresentar ao conhecimento geral os valores fixados pelo legislador em relação às circunstâncias sociais (NOGUEIRA, 2003).

O planejamento tributário é de suma importância para permanência e competitividade das empresas no mercado, pois sua realização representa a busca por soluções pragmáticas nas diversas questões de natureza tributária decorrentes do dia-adia operacional das empresas industriais, mercantis e de prestação de serviços, através de práticas lícitas capazes de excluir, reduzir ou postergar o ônus fiscal. Para Souza (2010, p. 38):

\footnotetext{
A necessidade de uma revisão geral no complexo sistema tributário brasileiro é conhecida por todos os segmentos da sociedade. A Reforma Tributária eliminará os obstáculos para uma produção mais eficiente e menos custosa, reduzirá a carga fiscal que incide sobre produtores e consumidores, estimulará a formalização e permitirá o desenvolvimento mais equilibrado de Estados e Municípios.
} 
Tratando-se de um Sistema Jurídico Tributário complexo composto por mais de 70 diferentes tipos de impostos, taxas e contribuições e dinâmico, tendo em vista as constantes alterações no ordenamento jurídico tributário. Enfim, torna-se indispensável à atuação de profissionais críticos, atualizados e criativos realizando a gestão tributária com base nas leis, os tratados e as convenções internacionais, os decretos e as normas complementares que versem, no todo ou em parte, sobre tributos e relações jurídicas a eles pertinentes, em busca da efetivação da elisão fiscal, impactando em um menor custo financeiro para as empresas e, consequentemente, maiores condições de permanência no mercado cada vez mais competitivo. Conforme Alexander Dias Siqueira (2011):

\begin{abstract}
A legislação tributária é demasiadamente ampla e complexa para ser conhecida em sua totalidade. Ao mesmo tempo é dinâmica, ou seja, recorrentemente sofre alterações. Por isso, o bom gestor tributário precisa estar sempre atento a tais mudanças, sabendo gerir as implicações sobre o negócio. (SIQUEIRA, 2011, p. 2).
\end{abstract}

Fica evidente, dessa forma, a necessidade da realização prévia do planejamento tributário por profissionais qualificados, mediante meios e instrumentos legítimos que visam harmonizar as transações futuras ao objeto de excluir, minimizar ou adiar a o correspondente débito fiscal, emanado de um Sistema Jurídico Tributário complexo e dinâmico. Do contrário, pode resultar em empreendimentos industriais, comercias e de serviços alto custo financeiro e, ao enfrentarem a competitividade de um mercado cada vez mais globalizado, vierem a falir.

\title{
Discussão e análise sobre planejamento tributário
}

Ante as considerações apresentadas, é possível afirmar que a carga tributária do país impede o crescimento das pequenas empresas em função das diversas limitações e restrições, as quais favorecem a arrecadação de impostos e contribuições unificados apenas para facilitarem a apuração, não reduzindo de forma significativa os tributos que as oneram. Tal condição gera consequências perversas ao ambiente, uma vez que as empresas, desassistidas de tão importante ferramenta, percorrem os caminhos da ilegalidade, inadimplência e informalidade, o que gera redução na arrecadação de tributos e investimento do poder público em suas cidades. A necessidade de um bom planejamento tributário, portanto, nos remete à premissa de que as micro e pequenas 
empresas têm grandes chances de se manterem no mercado com sucesso e dentro das bases legais, se desenvolverem a prática do planejamento tributário.

O planejamento tributário, portanto, interessa não somente aos empresários, como também ao poder público, enquanto importante agente de transformação social, torna-se um mecanismo cada vez mais fundamental à manutenção de uma boa relação das empresas com a fiscalização tributária. Assegura-se, assim, uma forma legítima e preventiva de redução, mas adimplência, de tributos, contribuindo para a competitividade e o crescimento das cidades médias, com vistas a maior qualidade de vida à sua população. Neste viés, cada empresa é importante que cada empresa verifique, adequadamente, as suas necessidades, seus recursos e optar pelo sistema de pagamento de tributos que mais lhe desonere (OLIVEIRA, 2009), mantendo, assim, o seu equilíbrio econômico e evitando a inadimplência.

\section{Considerações Finais}

A finalidade principal do planejamento tributário é a diminuição dos tributos dentro da lei, para que as empresas recolham menos impostos aos cofres públicos. Os tributos (impostos, taxas e contribuições) compõem a maior parcela dos custos das organizações, quando não são a maior. Na atualidade, a administração dos tributos tornou-se uma questão de sobrevivência empresarial e pública. Sendo assim, é imprescindível que as empresas, sejam elas de pequeno, médio ou grande porte, adotem um sistema de planejamento tributário. Face aos altos custos das demandas judiciais, é importante planejar o caminho a ser seguido previamente para evitar futuros transtornos. Muitas vezes o resultado de anos de trabalho, são desfeitos em consequência da soma de pequenos erros, cometidos no passado e do agravamento de problemas não solucionados.

Desse modo, conclui-se que o objetivo deste artigo foi alcançado com êxito, visto que as reflexões sobre o planejamento tributário, enquanto promotor da firmeza no futuro da empresa e da melhoria da qualidade de vida de uma população e a previsão de possíveis problemas a serem enfrentados, fora debatido. Conclui-se que tal planejamento constitui-se em ferramenta imperativa à capacidade de as empresas se manterem efetivas no mercado, evitando o caminho da informalidade e gerando renda ao poder público, o que permite a implementação e melhoria de sua infraestrutura e 
equipamentos urbanos, que, em um processo de retroalimentação, favorece o bom funcionamento das empresas. O Contador exerce, portanto, papel fundamental no planejamento, pois, é seu trabalho ser conhecedor da legislação vigente, e um importante colaborador na gestão dos negócios.

\section{Referências}

BORGES, H. B. Planejamento tributário: IPI, ICMS e ISS. 5. ed. São Paulo: Atlas, 2002.

BRASIL. Código Tributário Nacional. A Legislação do CTN. Vademecum, Saraiva, 2010. Saraiva, 2010.

Constituição da República Federativa do Brasil de 1988. Vademecum,

Lei Complementar $\mathbf{n}^{0}$ 123, de 14 de dezembro de 2006. Institui o Estatuto Nacional da Microempresa e da Empresa de Pequeno Porte. DOU, Brasília, DF, $15 \mathrm{dez}$. $2006,185^{\circ}$ da Independência e $118^{\circ}$ da República.

Lei $n^{0}$ 9.317, de 5 de dezembro de 1996. Dispõe sobre o regime tributário das microempresas e empresas de pequeno porte, institui o Sistema Integrado de Pagamento de Impostos e Contribuições das Microempresas e das Empresas de pequeno porte SIMPLES e dá outras providências. Diário Oficial da União (DUO), Brasília, DF, 06 dez. 1997. Seção 1, p. 25973 a 25977.

CASSONE, Vittorio. Direito Tributário. 16 ed. São Paulo: Atlas, 2004.

DEMO, Pedro. Introdução à metodologia da ciência. $2^{\mathrm{a}}$ ed. São Paulo: Atlas, 2000. FABRETTI, Láudio Camargo. Contabilidade Tributária. 10.ed. São Paulo. Atlas. 2006.

GRECO, Marco Aurélio. Planejamento Fiscal e Interpretação da Lei Tributária. São Paulo: Dialética, 2009.

MACHADO, Hugo de Brito. Curso de direito tributário. 26 ed. São Paulo: Malheiros, 2005.

MARTINS, Sérgio Pinto. Direito tributário. São Paulo: Saraiva, 2009.

OLIVEIRA, Gustavo Pedro. Contabilidade tributária. São Paulo: Saraiva, 2.ed., 2009.

MOTTA FILHO, Hélio Pereira da. Planejamento tributário: como obter na pequena empresa maiores resultados pagando legalmente menos impostos. $100 \mathrm{f}$. Dissertação em Mestrado Universidade de Santa Catarina. 2008.

NOGUEIRA, Rui Barbosa. Curso de Direito Tributário. 5 edição. São Paulo: Saraiva, 2003. 
SANTOS, Jémison Mattos dos. Estratégias de convivência para a conservação dos recursos naturais e mitigação dos efeitos da desertificação no semiárido. In LIMA, Ricardo da Cunha Correia, et all. Desertificação e mudanças climáticas no semiárido brasileiro. Campina Grande: IN-PB, 2011.

SIQUEIRA, Alexander Dias. GESTÃO TRIBUTÁRIA: Revista CEPPG - CESUC Centro de Ensino Superior de Catalão, Ano XIV, No 24 - $1^{\circ}$ Semestre/2011.

SOUZA, Maria Carolina de Azevedo F. de. Pequenas e médias empresas na reestruturação industrial. Brasília: SEBRAE, 2010.

YOUNK, Lúcia Helena Brisck. Planejamento tributário. $4^{\mathrm{o}}$ ed. $1^{\mathrm{a}}$ reimpr. Curitiba: Juruá, 2009.

ZAPATEIRO, José Alexandre. Teoria e prática de direito tributário e execução fiscal. $2^{\text {a }}$ Ed. Leme: Mizuno, 2007.

Recebido em: 22/10/2017

Aceito para publicação em: 30/11/2017 